\title{
Toxicity of the insect growth regulator novaluron to the non-target predatory bug Podisus maculiventris (Heteroptera: Pentatomidae)
}

\author{
G.C. Cutler ${ }^{\text {a,* }}$, C.D. Scott-Dupree ${ }^{\text {a }}$, J.H. Tolman ${ }^{\text {b }, ~ C . R . ~ H a r r i s ~}{ }^{\text {a }}$ \\ ${ }^{a}$ Department of Environmental Biology, Ontario Agricultural College, University of Guelph, Guelph, Ont., Canada N1G 2 W1 \\ ${ }^{\mathrm{b}}$ Southern Crop Protection and Food Research Centre, Agriculture and Agri-Food Canada, 1391 Sandford St., London, Ont., Canada N5V 4T3
}

Received 16 September 2005; accepted 22 December 2005

Available online 17 February 2006

\begin{abstract}
Novaluron is a novel insect growth regulator that exhibits potent insecticidal activity against the Colorado potato beetle, Leptinotarsa decemlineata (Say). The predatory bug Podisus maculiventris (Say) is a natural enemy of the potato beetle found throughout North America, and is widely available commercially. Anticipating the use of novaluron in L. decemlineata management, we conducted laboratory experiments to determine the susceptibility of $P$. maculiventris to novaluron. Although there was a 2- to 3-day delay in the onset of toxic effects, second instars were susceptible by direct contact and through exposure to potato foliage treated with field rates. When $P$. maculiventris eggs were dipped in field rate novaluron solutions, there was no significant effect on percent hatch, but there was subsequently a sharp decrease in the ability of hatched nymphs to molt. Similarly, fifth instars actively preyed on L. decemlineata larvae dipped in field rate novaluron solutions, but were thereafter unable to molt into adults. Female $P$. maculiventris adults caged with L. decemlineata larvae and novaluron treated potato plants had reduced longevity compared to those caged with untreated potato plants. Further, oviposition and hatch of eggs from adults on novaluron treated plants was significantly reduced. Although novaluron has demonstrated selectivity in favor of beneficial insects in other studies, these results suggest that P. maculiventris would be adversely affected. (C) 2006 Elsevier Inc. All rights reserved.
\end{abstract}

Keywords: Leptinotarsa decemlineata; Podisus maculiventris; Novaluron; Insect growth regulator; Non-target toxicity; Sublethal toxicity; Biological control

\section{Introduction}

The Colorado potato beetle, Leptinotarsa decemlineata (Say) (Coleoptera: Chrysomelidae), is the most important defoliator of potato in North America and is considered one of the most significant agricultural pests worldwide. Heavy reliance on chemical insecticides to manage L. decemlineata has resulted in rapid development of resistance to virtually all insecticides used against it (Bishop and Grafius, 1996; Hare, 1990; Mota-Sanchez et al., 2005). In an attempt to reduce reliance on broad-spectrum insecticides and to manage the resistance problem, extensive

\footnotetext{
${ }^{*}$ Corresponding author. Fax: +1 5198370442.

E-mail address: cutler@uoguelph.ca (G.C. Cutler).
}

research has been dedicated to integrating biological control into $L$. decemlineata management. Stinkbugs (Heteroptera: Pentatomidae) are the most specialized L. decemlineata predators (Cloutier et al., 2002). The most common pentatomid species attacking $L$. decemlineata are the two-spotted stinkbug, Perillus bioculatus (F.), and the spined soldier bug, Podisus maculiventris (Say) (Casagrande, 1987). P. bioculatus appears to be a $L$. decemlineata specialist, suggesting it would be a preferred candidate for inundative releases, where impacts on non-target species would be of concern (Cloutier et al., 2002; Hough-Goldstein, 1996). However, laboratory and field studies have found $P$. maculiventris to be as effective in controlling L. decemlineata populations (Biever and Chauvin, 1992; Hough-Goldstein and McPherson, 1996), and while 
commercial mass production of $P$. bioculatus has been problematic, $P$. maculiventris is available from many biological control suppliers. Thus, the latter is currently a more viable option for augmentative control of $L$. decemlineata.

Although stinkbug augmentation has successfully controlled L. decemlineata in field studies (Biever and Chauvin, 1992; Cloutier and Bauduin, 1995; Cloutier and Jean, 1998; Hough-Goldstein and McPherson, 1996), sole reliance on biological control as a management tactic has usually failed to provide effective control of the pest, especially at high population densities (Ferro, 1994; Hare, 1990). Nonetheless, growers could gain significant benefit from predators for control of $L$. decemlineata if they were not eliminated by frequent broad-spectrum insecticide use (Cloutier et al., 2002), suggesting that biorational, selective insecticides could be key in increasing the role of biological control in $L$. decemlineata management. Indeed, potato insect pest management programs that have adopted selective insecticides within conventional potato production have achieved high yields and low pest densities equivalent to conventional fields treated with broad-spectrum insecticides, with the added advantage of conserving high predator densities (Hilbeck et al., 1998; Koss et al., 2005; Reed et al., 2001). In addition, biorational compounds have modes of action different from those of broad-spectrum insecticides, making them useful tools in resistance management programs.

Novaluron (1-[3-chloro-4-(1,1,2-trifluoro-2-trifluoromethoxy-ethoxy)phenyl]-3-(2,6- difluorobenzoyl)urea) is a novel benzoylphenyl urea insect growth regulator that exhibits potent insecticidal activity against several important foliage feeding insect pests (Cutler et al., 2005a; Ishaaya et al., 2002, 2001; Malinowski and Pawinska, 1992). By inhibiting chitin formation, novaluron selectively targets larval insect stages, thus minimizing impacts on adults of non-target species and giving it potential in integrated pest management (IPM) programs. It had no effect on phytoseiid mite field populations (Ishaaya et al., 2001), mortality and development of the soil-dwelling predatory mite, Stratiolaelaps scimitus (Womersley) (Cabrera et al., 2005), and greenhouse populations and percent parasitism of the parasitoid Encarsia formosa Gahan (Ishaaya et al., 2002). It was found to have to no acute toxicity to rove beetles, Atheta coriaria Kraatz (S. Jandricic, personal communication), and bumble bees, Bombus impatiens Cresson or leafcutter bees, Megachile rotundata (F.) (A. King, personal communication). Novaluron is currently registered for use against $L$. decemlineata in the US (trade name Rimon), and is undergoing registration in Canada. It demonstrated potent activity against $L$. decemlineata larvae in the laboratory (Cutler et al., 2005a) and provided excellent prolonged control in field experiments (Malinowski and Pawinska, 1992). However, the toxicity of novaluron to natural enemies of $L$. decemlineata has not been evaluated, meaning the IPM potential of novaluron in $L$. decemlineata management is unclear.

A number of researchers have studied the impact of pesticides on stinkbug predators (De Clercq et al., 1995; De
Cock et al., 1996; Hough-Goldstein and Keil, 1991; Mohaghegh et al., 2000; Tillman and Mullinix, 2004; Vandekerkhove and De Clercq, 2004; Wilkinson et al., 1979; $\mathrm{Yu}, 1988)$. Anticipating the use of novaluron in future $L$. decemlineata management, we investigated the susceptibility of $P$. maculiventris to novaluron. Tests were conducted exposing $P$. maculiventris nymphs and eggs to novaluron through direct contact. As $P$. maculiventris is an omnivore, further experiments were conducted exposing bugs to novaluron treated $L$. decemlineata larvae and potato foliage. For comparison, nymphs and eggs also were exposed to imidacloprid, a neonicotinoid insecticide used widely in $L$. decemlineata management in North America. Finally, an experiment was done to determine if adult $P$. maculiventris fed novaluron treated potato foliage and $L$. decemlineata larvae experienced sublethal effects on lifespan and reproduction. The viability of progeny from these adults was also assessed.

\section{Materials and methods}

\subsection{Insects}

Podisus maculiventris adults were obtained from Dr. Christine Noronha, Crops and Livestock Research Center, Agriculture and Agri-Food Canada, Charlottetown, Prince Edward Island, Canada. The colony was founded in 2002 from adults purchased from the Bug Factory (Nanoose Bay, British Columbia, Canada), and maintained in insecticide-free environment. In this study, $P$. maculiventris were reared on mealworms, Tenebrio molitor L. (Coleoptera: Tenebrionidae) $\left(25 \pm 1{ }^{\circ} \mathrm{C}, 16: 8\right.$ (L:D), $\left.65 \pm 5 \% \mathrm{RH}\right)$. Cotton wicks soaked with tap water were provided to all stages as a moisture source. $L$. decemlineata used in experiments were from an insecticide-susceptible strain reared for over 60 generations on potato foliage $\left(27 \pm 1{ }^{\circ} \mathrm{C}, 16: 8(\mathrm{~L}: \mathrm{D}), 65 \pm 5 \% \mathrm{RH}\right)$ at the Southern Crop Protection and Food Research Centre, Agriculture and Agri-Food Canada in London, Ontario.

\subsection{Nymph direct contact exposure}

Technical grade novaluron (96.0\% purity, MakhteshimAgan of North America, Raleigh, NC) and imidacloprid (97.9\% purity, Bayer CropScience Canada, Calgary, AB) were dissolved in acetone + olive oil $(19+1$ by volume $)$ to produce concentrations ranging from 1 to $1000 \mathrm{ppm}$. Controls consisted of insects treated with the acetone + olive oil solvent only. Insecticide was applied to the insects with a Potter spray tower using methods similar to those described by Harris et al. (1962). Second instars were immobilized by placing them in a $6{ }^{\circ} \mathrm{C}$ fridge for $30 \mathrm{~min}$ prior to exposure to insecticides. Groups of 10 second instars were subsequently placed dorsal surface up on filter paper in glass petri dishes $(100 \times 15 \mathrm{~mm})$, placed in the spray tower, and sprayed with $5 \mathrm{ml}$ of insecticide solution. Treated insects were transferred to 
disposable petri dishes $(90 \times 15 \mathrm{~mm})$ containing five mealworms, a water-soaked cotton wick $(30 \mathrm{~mm})$ and potato foliage, and were maintained at $25 \pm 1{ }^{\circ} \mathrm{C}, 16: 8$ (L:D), and $65 \pm 5 \% \mathrm{RH}$. Mealworms, water and foliage were replenished as needed (usually every second day), and mortality was recorded after five days. There were at least four replicates per concentration and each assay was repeated a minimum of two times, providing a sample size of at least 80 insects per concentration. Seven concentrations producing approximately $5-95 \%$ mortality were used for each insecticide. Concentrations lethal to $50 \%\left(\mathrm{LC}_{50}\right)$ and $95 \%$ $\left(\mathrm{LC}_{95}\right)$ of the nymphs, confidence limits $(\mathrm{CL})$, and slopes were determined by probit analysis (SAS Institute, 2001).

\subsection{Nymph exposure to treated foliage}

The proposed Canadian label for novaluron (Rimon 10EC, $100 \mathrm{~g} \mathrm{AI} / \mathrm{L}$, Makhteshim-Agan of North America, Raleigh, NC), recommends an application rate of 220 $878 \mathrm{ml} /$ ha for L. decemlineata control (R. Everich, personal communication). At a spray volume of $350 \mathrm{~L} / \mathrm{ha}$ - traditionally felt to be the minimum volume for effective potato canopy coverage in Ontario (OMAF, 2004)-the concentration of novaluron in spray solutions at an application rate of $250 \mathrm{ml} / \mathrm{ha}$ would be approximately: $250 \mathrm{ml} / \mathrm{ha} \times 1 \mathrm{~L} / 1000 \mathrm{ml} \times 100 \mathrm{~g} \quad \mathrm{AI} / \mathrm{L} \times 1 \mathrm{ha} / 350 \mathrm{~L} \times 1$ $\mathrm{L} / 1000 \mathrm{~g} \times 1,000,000 \mathrm{ppm}=71 \mathrm{ppm}$. A spray solution applied at $875 \mathrm{ml} /$ ha would have a novaluron concentration of approximately $250 \mathrm{ppm}$. The Canadian label for imidacloprid (Admire 240F, $240 \mathrm{~g}$ AI/L, Bayer CropScience Canada, Calgary, AB), recommends applications of $200 \mathrm{ml} / \mathrm{ha}$ for $L$. decemlineata control, giving an imidacloprid concentration of approximately $137 \mathrm{ppm}$ in a spray solution applied at a volume of $350 \mathrm{~L} / \mathrm{ha}$. Therefore, Rimon 10EC and Admire 240F were each suspended in deionized water to give stock solutions of $1000 \mathrm{ppm}$. Dilutions were subsequently made to produce 71 and $250 \mathrm{ppm}$ novaluron solutions, representing "low-" and "high-rate" field applications, respectively. A $137 \mathrm{ppm}$ imidacloprid solution was prepared representing the typical field application rate applied for $L$. decemlineata control.

Four centimeter diameter discs were cut from potato leaves with a stainless steel cork borer. Discs were dipped in deionized water or insecticide solution for approximately $6 \mathrm{~s}$ and placed on a wire rack until dry. The dry discs were then placed individually in sterile Gelman $47 \mathrm{~mm}$ microbiological dishes, each containing a $42.5 \mathrm{~mm}$ diameter filter paper. Five $P$. maculiventris second instars were placed on to each leaf disc and each dish was covered. There were 10 replicates per treatment. The dishes were arranged in a randomized complete block design and transferred to a holding room $\left(25 \pm 1{ }^{\circ} \mathrm{C}, 16: 8(\mathrm{~L}: \mathrm{D}), 65 \pm 5 \% \mathrm{RH}\right)$. Insects were allowed to feed on potato foliage for $48 \mathrm{~h}$ and then were transferred to clean plastic petri dishes $(50 \times 15 \mathrm{~mm})$ containing untreated potato foliage, a cotton wick saturated with deionized water, and two mealworms. Mortality was recorded after 2 (i.e., when insects were transferred to clean foliage), 4, 6, and 8 days, and foliage and water were replenished as needed. Percent mortality data were arcsine transformed (Zar, 1996) and analyzed for treatment and time effects over the whole experiment using repeated measures ANOVA. Means were separated between treatments on separate days using the Tukey test $(\alpha=0.05)$ (SAS Institute, 1997). Back-transformed data are presented in the results.

\subsection{Nymph food chain exposure through treated L. decemlineata larvae}

Third instar $L$. decemlineata were individually dipped in deionized water, 71, or $250 \mathrm{ppm}$ novaluron for $4 \mathrm{~s}$, placed dorsal side up on glass petri plates $(100 \times 15 \mathrm{~mm})$ and air dried for $1 \mathrm{~h}$. Novaluron solutions were prepared as described Section 2.3. For each treatment, three third instar $L$. decemlineata were placed in a plastic petri dish $(50 \times 15 \mathrm{~mm})$ containing a water-soaked cotton wick and potato foliage. A fifth instar $P$. maculiventris nymph held without food for $24 \mathrm{~h}$ was then added to each dish. Dishes were covered, moved to a holding room $\left(25 \pm 1{ }^{\circ} \mathrm{C}, 16: 8\right.$ (L:D), $65 \pm 5 \% \mathrm{RH}$ ), and monitored daily. After the initial three $L$. decemlineata larvae were eaten, untreated larvae were added to each dish ad lib. Fresh potato foliage and water were replenished as needed. Each day the number of consumed larvae and dead P. maculiventris were recorded, and dead larvae were removed. If $P$. maculiventris fifth instars molted, the time to molt (days after initiation of the experiment) was recorded. Adults were provided water and $L$. decemlineata larvae as needed and monitored for up to 5 days after molt, but larval consumption during this stadium was neither recorded nor used in analyses. The experiment was arranged in a randomized complete design with eight replicates per treatment. The effect of novaluron treated $L$. decemlineata third instars on $P$. maculiventris nymph predation (time to consume the initial 3 larvae and total larvae consumed) was analyzed by ANOVA. Data were square root transformed before analysis using the equation $X^{\prime}=\sqrt{X+0.5}$ (Zar, 1996), as a ShapiroWilk test found the data to be non-normal (SAS Institute, 1997). The effect of consumption of novaluron treated $L$. decemlineata larvae on $P$. maculiventris nymph molting ability was determined by contingency table analysis (SAS Institute, 1997). Back-transformed data are presented in the results.

\subsection{Ovicidal activity}

Podisus maculiventris egg masses (mean $=15.8$ eggs per egg mass; range $=9-29$ eggs per egg mass) were clipped from paper towel pieces that served as oviposition sites for caged adults. Egg masses were individually dipped in deionized water, $71 \mathrm{ppm}$ novaluron, $250 \mathrm{ppm}$ novaluron, or $137 \mathrm{ppm}$ imidacloprid for $4 \mathrm{~s}$, individually placed in sterile Gelman $47 \mathrm{~mm}$ microbiological dishes, and transferred to a holding room $\left(25 \pm 1{ }^{\circ} \mathrm{C}, 16: 8(\mathrm{~L}: \mathrm{D}), 65 \pm 5 \% \mathrm{RH}\right)$. 
Solutions were prepared as described in Section 2.3. On hatching, egg masses were placed on a cotton wick saturated with deionized water. Two days later neonates were counted and percent hatch was determined. Insects were held until they molted into second instars or died. The experiment was arranged in a randomized complete design with six replicates per treatment. Percent hatch and molt of neonates, and time to hatch was compared among treatments by ANOVA with means separation by the Tukey test $(\alpha=0.05)$ (SAS Institute, 1997). Percent hatch and molt data were arcsine transformed before analysis (Zar, 1996). Time to hatch data were square root transformed before analysis, as described in Section 2.4, as a ShapiroWilk test found these data to be non-normal (SAS Institute, 1997). Back-transformed data are presented.

\subsection{Effects on adult P. maculiventris}

Effects of novaluron on $P$. maculiventris adults feeding on novaluron treated potato foliage were determined. Potato plants were grown in an insecticide-free greenhouse in $100 \mathrm{~mm}$ diameter pots containing Pro-Mix potting soil. Plants (20-30 cm high) were removed from the greenhouse and treated with insecticide outside. Insecticides were applied in water at a rate of $900 \mathrm{~L} / \mathrm{ha}$ using a hand-held, $\mathrm{CO}_{2}$ pressurized, $\mathrm{R} \& \mathrm{D}$ plot sprayer fitted with a single D-4 orifice disc and a \#25 swirl plate. Rimon 10EC was applied at rates of $25 \mathrm{~g} \mathrm{AI} / \mathrm{ha}$ (low-rate) or $850 \mathrm{~g} \mathrm{AI} / \mathrm{ha}$ (high-rate) in water. Plants were allowed to air dry and were then transferred to a holding room $\left(25 \pm 1{ }^{\circ} \mathrm{C}, 16: 8\right.$ (L:D), $65 \pm 5 \% \mathrm{RH}$ ). Adult $P$. maculiventris were collected from rearing cages the same day plants were treated with insecticide. Groups of approximately 20 newly emerged adults were added to cages containing untreated potato plants, low-rate plants, or high-rate plants, each containing approximately 25 third/fourth instar $L$. decemlineata. Adults fed on $L$. decemlineata larvae and potato plants for 3-4 days before male and females copulated. Mating pairs were then moved to separate oviposition cages (one pair per cage) containing two control plants, two low-rate plants, or two high-rate plants. There were five replicates (5 mating pairs) per treatment. Three third/fourth instar $L$. decemlineata were added to each cage and replenished as needed. Oviposition cages consisted of potted plants placed in plastic trays containing sand, covered with an open-bottomed cage $(30 \times 30 \times 40 \mathrm{~cm}$ high $)$ screened with $500 \mu \mathrm{m}$ black mesh. Numbers of egg masses laid and eggs per egg mass were recorded daily for up to 21 days. Newly deposited egg masses were clipped from plants or removed from the side of the cages, placed individually in $50 \mathrm{~mm}$ diameter plastic petri dishes containing a cotton wick $(20 \mathrm{~mm})$ saturated in distilled water, and were maintained in the same holding room as the caged plants. Hatch of each egg mass was monitored daily and first instars were held in the petri dishes until they molted or died. If a $P$. maculiventris adult died, the date of death and sex was recorded. The surviving adult was left to feed and oviposit (if a female) until it died, up to 21 days after initiation of the experiment. As well, qualitative observations on adult behavior were made.

Differences in longevity of male and female P. maculiventris adults were compared among treatments by ANOVA. The number of egg masses laid per female, the number of eggs per egg mass, percent hatch of eggs, and percent molt of nymphs from eggs were analyzed for treatment and time effects over the whole experiment using a general linear model (SAS Institute, 1997). Multiple comparisons where conducted by the Tukey test $(\alpha=0.05)$. Back-transformed data are presented in the results.

\section{Results}

\subsection{Nymph direct contact exposure}

Novaluron was toxic to $P$. maculiventris nymphs by direct contact; application of a solution containing only $18.7 \mathrm{ppm}$ was needed to kill $50 \%$ of second instars (Table 1). It was generally less toxic to second instars than imidacloprid by direct contact. The difference in toxicity between these compounds was significant at the $\mathrm{LC}_{50}$, as indicated by the lack of overlap of the $95 \% \mathrm{CL}$, but not at the $\mathrm{LC}_{95}$ (Table 1).

\subsection{Nymph exposure to treated foliage}

There was a significant effect of treatment $(F=15.28$; $d f=3 ; \quad P<0.0001) \quad$ and time $\quad(F=113.06 ; \quad d f=3$; $P<0.0001)$ on $P$. maculiventris nymph mortality during exposure to treated potato foliage (Fig. 1). A significant treatment-time interaction was also found $(F=11.20$; $d f=9 ; P<0.0001)$. Although there was no treatment effect after 2 days $(F=2.82 ; d f=3 ; P=0.052$-marginally insignificant at $\alpha=0.05$ ), a significant increase in nymph mortality due to treatment was found after $4(F=3.15$; $d f=3 ; P=0.037), 6(F=30.22 ; d f=3 ; P<0.0001)$, and $8(F=41.21 ; d f=3 ; P<0.0001)$ days. After 4 days, nymph mortality was highest on the imidacloprid treated foliage, although the difference was not significant compared to the control or high-rate novaluron treatment $(\alpha=0.05)$. After 6 and 8 days, however, nymphs exposed to both highand low-rate novaluron treated potato foliage had significantly higher mortality than the other treatments. Second instars in the novaluron treatments usually molted, but died as third instars. These third instars displayed symptoms of sublethal intoxication, including lethargy and ataxia, and often were unable to shed their exuvia. All nymphs

Table 1

Direct contact toxicity of novaluron and imidacloprid to P. maculiventris second instars 5 days after treatment

\begin{tabular}{lclccl}
\hline Insecticide & $n$ & $\begin{array}{l}\text { Slope } \\
( \pm \mathrm{SEM})\end{array}$ & $\chi^{2}$ & $\begin{array}{l}\mathrm{LC}_{50}(95 \% \mathrm{CL}) \\
(\mathrm{ppm})\end{array}$ & $\begin{array}{l}\mathrm{LC}_{95}(95 \% \mathrm{CL}) \\
(\mathrm{ppm})\end{array}$ \\
\hline $\begin{array}{l}\text { Novaluron } \\
\text { Imidacloprid }\end{array}$ & 676 & $1.07(0.24)$ & 0.71 & $18.7(9.8-27.4)$ & $65.0(28.6-779.2)$ \\
\hline
\end{tabular}




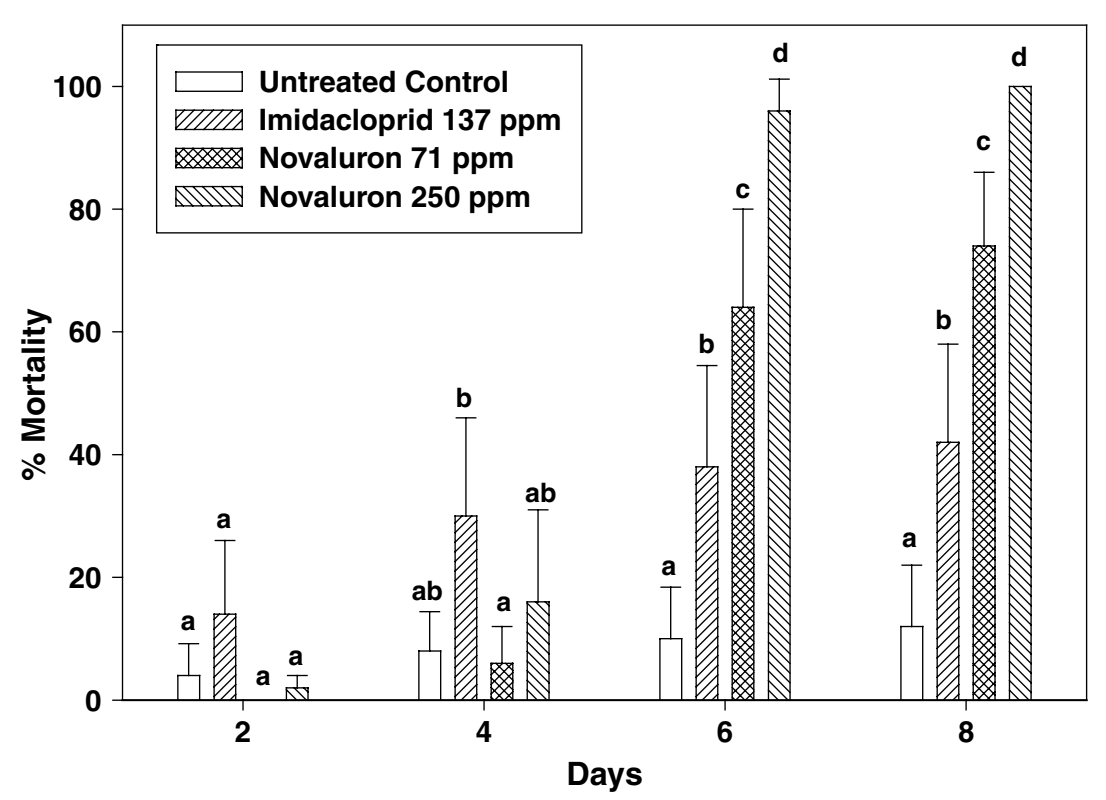

Fig. 1. Mortality $( \pm 95 \% \mathrm{CL}$ ) of P. maculiventris second instars after exposure to untreated, imidacloprid (Admire 240F), or novaluron (Rimon 10EC) treated foliage. Nymphs were exposed to treated foliage for $48 \mathrm{~h}$ and thereafter transferred to clean containers with untreated foliage, water, and prey (Tenebrio molitor) for the remainder of the experiment. Percent data were arcsine transformed for analysis; back-transformed data are presented. Bars with different letters above them, for a given day, are significantly different $(P \leqslant 0.05$, Tukey test).

exposed to high-rate novaluron treated foliage died by the end of the experiment, while about $75 \%$ died on the lowrate foliage (Fig. 1). Although about $60 \%$ of second instars from the imidacloprid treatment molted and remained alive after 8 days, survivors displayed symptoms of sublethal intoxication similar to those observed in the novaluron treatment. In all treatments, nymphs were observed feeding on plant juices, especially early in the experiment.

\subsection{Nymph food chain exposure through treated $L$. decemlineata larvae}

Fifth instar $P$. maculiventris that were held without food for $24 \mathrm{~h}$ readily preyed on $L$. decemlineata larvae. There was no significant difference in time taken to eat the initial three larvae, whether they were untreated or dipped in high- or low-rate novaluron solutions $(F=1.40 ; d f=2$; $P=0.28$ ). There was a marginally significant effect of treatment on total number of larvae eaten by $P$. maculiventris nymphs during the fifth stadium $(F=3.478 ; \quad d f=2$; $P=0.049)$, although there was no significant difference in the duration of this stadium $(F=2.518 ; d f=2 ; P=0.10)$ (Table 2). In addition, there was a major reduction in molting ability of fifth instars after feeding on L. decemlineata larvae treated with novaluron $\left(\chi^{2}=25.73 ; \quad d f=2\right.$; $P<0.0001$ ) (Table 2). While $100 \%$ of nymphs that fed on untreated $L$. decemlineata larvae molted and lived to the end of the experiment, no adult emergence was observed in nymphs that fed on low-rate novaluron treated larvae, and only 1 nymph exposed to the high-rate novaluron treated larvae molted. The emerged $P$. maculiventris adult from the high-rate treatment displayed symptoms of sublethal intoxication, including lethargy, ataxia, incomplete wing formation, and abstention from feeding and drinking, and died 4 days after molt. In most cases, nymphs exposed to novaluron treated $L$. decemlineata larvae died before ecdysis, although insects died during ecdysis in a few replicates. Fifth instars that fed on untreated $L$. decemlineata larvae molted after approximately 4 days, resulting in adults with normal morphology and behavior.

\subsection{Ovicidal activity}

When eggs were dipped in novaluron or imidacloprid solutions, there was no significant effect on days to hatch after treatment $(F=2.46 ; d f=3 ; P=0.092$ ) or on the percent hatch of treated eggs $(F=1.73 ; d f=3 ; P=0.193)$. However, the ability of first instars from treated eggs to molt

Table 2

Effects of novaluron on fifth instar P. maculiventris through exposure to treated third instar $L$. decemlineata

\begin{tabular}{|c|c|c|c|c|}
\hline Treatment & $\begin{array}{l}\text { Days in fifth stadium } \\
( \pm \text { SEM })^{\mathrm{A}}\end{array}$ & $\begin{array}{l}\text { Days to consume } 3 \text { initial } \\
\text { L. decemlineata larvae }( \pm \mathrm{SEM})\end{array}$ & $\begin{array}{l}\text { Total } L \text {. decemlineata } \\
\text { larvae consumed }( \pm \text { SEM })\end{array}$ & $\begin{array}{l}\text { Mean \% molt } \\
( \pm 95 \% \mathrm{CL})^{\mathrm{B}}\end{array}$ \\
\hline Control & $4.4(0.5) \mathrm{a}$ & $1.6(0.2) \mathrm{a}$ & $2.9(0.7) \mathrm{a}$ & $100(0) \mathrm{a}$ \\
\hline Novaluron, 71 ppm & $5.9(0.5) \mathrm{a}$ & $1.4(0.2) \mathrm{a}$ & $4.0(0.3) \mathrm{ab}$ & $0(0) \mathrm{c}$ \\
\hline Novaluron, $250 \mathrm{ppm}$ & $6.9(1.2) \mathrm{a}$ & $1.5(0.3) \mathrm{a}$ & $5.9(1.3) \mathrm{b}$ & $12.5(6.7) \mathrm{b}$ \\
\hline
\end{tabular}

A Means within columns followed by the same letter are not significantly different $(P \leqslant 0.05$, Tukey test).

B Percent data were arcsine transformed before analysis. Back-transformed data are presented. 
Table 3

Effect of novaluron and imidacloprid on $P$. maculiventris egg hatch and subsequent molt of first instars (N1)

\begin{tabular}{llll}
\hline Treatment & $\begin{array}{l}\text { Mean days } \\
\text { to hatch } \\
( \pm \mathrm{SEM})^{\mathrm{A}}\end{array}$ & $\begin{array}{l}\text { Mean \% hatch } \\
( \pm 95 \% \mathrm{CL})^{\mathrm{B}}\end{array}$ & $\begin{array}{l}\text { Mean \% N1 molt } \\
( \pm 95 \% \mathrm{CL})\end{array}$ \\
\hline Control & $3.3(0.4) \mathrm{a}$ & $94.1(7.2) \mathrm{a}$ & $100(0) \mathrm{a}$ \\
Novaluron, 71 ppm & $3.0(0.8) \mathrm{a}$ & $79.3(25.5) \mathrm{a}$ & $6.7(13.2) \mathrm{b}$ \\
Novaluron, 250 ppm & $4.3(0.5) \mathrm{a}$ & $89.9(6.8) \mathrm{a}$ & $0(0) \mathrm{c}$ \\
Imidacloprid, 137 ppm & $4.8(0.4) \mathrm{a}$ & $68.7(23.4) \mathrm{a}$ & $6.8(6.8) \mathrm{b}$ \\
\hline
\end{tabular}

$\overline{\mathrm{A}}$ Means within columns followed by the same letter are not significantly different $(P \leqslant 0.05$, Tukey test $)$

B Percent data were arcsine transformed before analysis. Back-transformed data are presented.

was significantly reduced $(F=105.88 ; d f=3 ; P<0.0001)$ in the treatments (Table 3 ). While first instars that emerged from novaluron treated eggs generally appeared healthy and survived up to ecdysis, there was no molt of nymphs from the high-rate solution and less than $10 \%$ molt of nymphs from the low-rate solution (Table 3). Many of the first instars from imidacloprid treated eggs exhibited sublethal signs of poisoning such as reduced mobility and feeding, and died within $24 \mathrm{~h}$ of hatch.

\subsection{Effects on adult P. maculiventris}

Adult $P$. maculiventris were observed feeding on plant juices and $L$. decemlineata throughout the experiment. $L$. decemlineata larvae often were able to feed on potato foliage over $24 \mathrm{~h}$ before being attacked by $P$. maculiventris adults. While there was no difference in longevity of $P$. maculiventris males on treated or untreated plants $(F=2.06 ; d f=2 ; P=0.17)$, we did find a treatment effect on female longevity $(F=6.34 ; d f=2 ; P=0.019)$ (Table 4). Although three females in control cages lived the full 21 days of the experiment, 2 from control cages were lost (escaped from cages and not recovered) on days 12 and 14. When the experiment was terminated at 21 days, 6 of 8 adults were still alive in the controls ( 2 females were lost), while only 2 of 19 adults remained alive in the novaluron treatments ( 1 female was lost).

Oviposition and hatch of eggs from adults on novaluron treated plants was significantly reduced (Table 4). Fewer egg masses were oviposited by females in the novaluron treatments $(F=4.69 ; d f=2 ; P=0.010)$, and there was a general decrease in oviposition of egg masses over time in each of the treatments (control: $F=3.18$; $d f=18 ; P=0.0002$, low-rate novaluron: $F=3.78 ; d f=18$; $P<0.0001$, high-rate novaluron: $F=3.00 ; \quad d f=18$; $P=0.0004)$. A total of 41,30 , and 22 egg masses were oviposited by $P$. maculiventris females in the control, low-rate, and high-rate novaluron treatments, respectively. There was no treatment-time interaction $(F=1.13 ; d f=36$; $P=0.30$ ) effect on egg mass oviposition. There also was a significant decrease in the number of eggs per egg mass $(F=4.17 ; d f=2 ; P=0.019)$ in the novaluron treatments
Table 4

Effect of feeding on novaluron treated potato foliage and $L$. decemlineata larvae on adult $P$. maculiventris longevity, egg production, egg hatch, and subsequent molt of emerged 1st instar nymphs (N1) ${ }^{\mathrm{A}}$

\begin{tabular}{llll}
\hline Biological parameter & \multicolumn{4}{l}{ Treatment mean $( \pm \mathrm{SEM})^{\mathrm{B}}$} \\
\cline { 2 - 4 } & Untreated & $25 \mathrm{~g} \mathrm{AI} / \mathrm{ha}$ & $85 \mathrm{~g} \mathrm{AI} / \mathrm{ha}$ \\
\hline Female longevity (days) & $21.0(0) \mathrm{a}$ & $14.8(1.4) \mathrm{b}$ & $18.3(1.1) \mathrm{ab}$ \\
Male longevity (days) & $19.8(1.0) \mathrm{a}$ & $15.8(2.0) \mathrm{a}$ & $16.0(1.7) \mathrm{a}$ \\
Egg masses/day & $0.4(0.06) \mathrm{a}$ & $0.3(0.07) \mathrm{ab}$ & $0.2(0.05) \mathrm{b}$ \\
Eggs/egg mass & $16.1(1.3) \mathrm{a}$ & $13.2(3.0) \mathrm{ab}$ & $10.9(1.9) \mathrm{b}$ \\
\% Hatch & $75.7(10.6) \mathrm{a}$ & $10.8(9.5) \mathrm{b}$ & $9.1(10.8) \mathrm{b}$ \\
\% Molt of hatched N1 & $92.9(1.7) \mathrm{a}$ & $12.2(4.5) \mathrm{b}$ & $0.0(0.0) \mathrm{c}$ \\
\hline
\end{tabular}

${ }^{\mathrm{A}}$ Upon emergence, virgin adult male and female $P$. maculiventris were placed on potato plants that were treated with water or novaluron with a hand-held sprayer ( $n=5$ per treatment). L. decemlineata larvae were added to cages ad lib. Adults fed and oviposited for up to 21 day after initiation of the experiment.

B Means within each row followed by the same letter are not significantly different $(P \leqslant 0.05$; Tukey test).

${ }^{C}$ Data were square root transformed for analysis. Back-transformed data are presented.

D Data were arcsine transformed for analysis. Back-transformed data are presented.

E Mean percent hatch and successful molt over 21 days.

(Table 4). While the number of eggs per egg mass did not change as the experiment progressed in the control $(F=1.86 ; d f=13 ; P=0.08)$ or high-rate novaluron treatment $(F=1.40 ; d f=9 ; P=0.28)$, a significant fluctuation over time in the number of eggs per egg mass was found in the low-rate novaluron treatment $(F=3.70 ; d f=8$; $P=0.008$ ). Over the whole experiment, females on untreated foliage laid 656 eggs, while females on low- and high-rate novaluron treated foliage laid 390 and 242 eggs, respectively. Although eggs were laid by $P$. maculiventris females in all treatments, there was a marked decrease in the hatch of eggs $(F=153.45 ; d f=2 ; P<0.0001)$ and subsequent molt of nymphs in the novaluron treatments. Only about $10 \%$ of eggs hatched in the novaluron treatments and none of the first instars molted from the high-rate treatment (Table 4).

Several behavioral observations indicated $P$. maculiventris adults in the novaluron treatments experienced effects of sublethal intoxication. Adults on treated plants sometimes displayed reduced walking ability, poor coordination, and ataxia. They sometimes fell off plants, remaining motionless on their backs. Only after probing with a needle or forceps was it clear that these adults were alive. Although we did not record the number of $L$. decemlineata larvae preyed on by adults throughout the experiment, qualitatively we did not notice any differences between the control and novaluron treatments in the number of larvae consumed.

\section{Discussion}

Podisus maculiventris is endemic throughout North America. A polyphagous predator of over 90 insect species (McPherson, 1982), its importance as a natural enemy is well recognized (Coll and Ruberson, 1998; Schaefer and 
Panizzi, 2000). Despite its potential for biological control of $L$. decemlineata, it is unlikely that $P$. maculiventris could consistently regulate this pest on its own, meaning exposure to insecticides would often occur. Heavy reliance on insecticides has, paradoxically, both exacerbated $L$. decemlineata insecticide resistance and has hindered optimal utilization of natural enemies. Therefore, increased use of compounds that could concurrently reduce pest densities, maintain high natural enemy populations, and curb resistance development would be particularly welcome in L. decemlineata management.

Although novaluron is generally considered a selective, reduced risk insecticide, our results indicate that all three $P$. maculiventris life stages would be susceptible to novaluron through several routes of exposure. The direct contact $\mathrm{LC}_{50}$ of novaluron for $P$. maculiventris second instars was $18.7 \mathrm{ppm}$, a concentration that falls within the range of toxicity of broad-spectrum insecticides reported by $\mathrm{Yu}$ (1988) and Hough-Goldstein and Keil (1991), albeit novaluron was less toxic than several of these compounds. Novaluron had similar direct contact toxicity to $L$. decemlineata second instars $\left(\mathrm{LC}_{50}=27 \mathrm{ppm}\right)$ (Cutler et al., 2005a). Considering that solutions of approximately $71-250 \mathrm{ppm}(250-875 \mathrm{ml} / \mathrm{ha})$ novaluron would be applied to control $L$. decemlineata, the direct contact selectivity for $P$. maculiventris nymphs would be negligible. In contrast, Bacillus thuringiensis var. san diego and cryolite were found to be practically non-toxic to $P$. bioculatus nymphs by topical exposure (Hough-Goldstein and Keil, 1991), as were topical applications of diflubenzuron, the first developed benzoylphenyl urea, to P. maculiventris (De Clercq et al., 1995). The selectivity of diflubenzuron is partly due to its tendency to remain in the cuticular waxes following direct contact (Retnakaran and Wright, 1987). Unfortunately, the increased direct contact efficacy of novaluron against several pest species (Cutler et al., 2005a; Ishaaya et al., 1998) may result in decreased selectivity in favor of beneficial species. The imidacloprid direct contact $\mathrm{LC}_{50}$ we found for $P$. maculiventris second instars was 13-fold lower than that measured by De Cock et al. (1996) for fifth instars. This discrepancy may reflect a greater susceptibility of younger instars to imidacloprid, intra-specific variation, or may simply be due to differing experimental methods. As with P. maculiventris, Cutler et al. (2005a) found that $L$. decemlineata larvae were more susceptible to imidacloprid than novaluron.

Podisus maculiventris second instars were highly susceptible to novaluron by exposure to treated foliage; $100 \%$ of nymphs died when exposed to foliage treated with the high recommended rate of novaluron, while about $75 \%$ died when exposed to the lower rate. The delay in the onset of novaluron toxicity was expected as it acts by inhibiting chitin synthesis, which occurs predominantly during molt. In addition to contact with treated foliage, the activity of novaluron in this experiment was probably due to ingestion since $P$. maculiventris is an omnivore requiring water and nutrients from plant juices, in addition to animal protein, for optimal growth and development (Ruberson et al.,
1986). Its susceptibility to novaluron treated potato foliage therefore highlights an additional challenge for the integration of omnivorous predators and insecticides in pest management programs. Not only must compounds of interest exhibit no residual toxicity to the natural enemy, but exposure also must be minimized through ingestion of plant material. Although not systemic, foliar applied novaluron does have trans-laminar activity (Ishaaya et al., 2002) and its biological activity may persist as long as 5 weeks after application (Cutler et al., 2005b). Thus, $P$. maculiventris nymphs could be exposed to lethal concentrations of novaluron on plant foliage for extended periods during searches for prey and colonization (or recolonization) of treated fields.

The response of $P$. maculiventris to other insecticides through residual contact and ingestion of treated water or plant juices has been variable. Wilkinson et al. (1979) found adults and nymphs to be highly susceptible to organophosphorus insecticides, but tolerant to the pyrethroids, fenvalerate, and permethrin through residual contact. Diflubenzuron was harmless to $P$. maculiventris nymphs by residual contact but was highly toxic when ingested via drinking water (De Clercq et al., 1995), as was imidacloprid (De Cock et al., 1996). Nymphs exposed to encapsulated $\lambda$-cyhalothrin by ingestion and residual contact quickly recovered after knock-down (Vandekerkhove and De Clercq, 2004). Hough-Goldstein and Keil (1991) reported that $P$. bioculatus nymphs were highly susceptible to esfenvalarate, oxamyl, and endosulfan through exposure to treated potato foliage, but were unaffected by exposure to B. thuringiensis and cryolite treated foliage.

Although $P$. maculiventris fifth instars readily preyed on L. decemlineata larvae dipped in field-rate novaluron solutions, adult emergence was almost completely suppressed. In some cases this resulted in prolongation of the fifth instar stadium and greater total predation during that stage in the novaluron treatments. Similarly, fifth instars fed pyriproxyfen treated Spodoptera exigua (Hübner) larvae suffered high mortality at molt (De Clercq et al., 1995). Adults and nymphs also were susceptible to prey treated with organophosphorus or neonicotinoid insecticides (Tillman and Mullinix, 2004). Hough-Goldstein and Keil (1991) found that $P$. bioculatus third instars were highly susceptible to endosulfan, and moderately so to esfenvalarate and oxamyl, but tolerant of $L$. decemlineata larvae treated with $B$. thuringiensis and cryolite.

Few studies have investigated ovicidal activity of insecticides on heteropteran eggs. We found that eggs dipped in field-rates of novaluron resulted in no reduction in percent hatch or adverse effects in behavior of first instars, but molt of emerging first instars was greatly diminished. Results with imidacloprid were comparable. In contrast, Hough-Goldstein and Keil (1991) found that applications of esfenvalarate, oxamyl, endosulfan, $B$. thuringiensis or cryolite to $P$. bioculatus eggs had no impact on hatch or mortality of hatched nymphs. Eggs of several pest species are susceptible to novaluron applications (Cutler et al., 2005a; Ishaaya et al., 2002, 1996). 
Emphasis on sublethal toxicological studies in entomology has increased in recent years. Insects that survive insecticide application may still suffer sublethal intoxication resulting in reduced longevity, developmental rates, numbers of offspring, and body weights. Behavioral effects such as reduced sexual competitiveness and ability to find food or resources also could occur (Starks and Banks, 2003). We found that longevity of $P$. maculiventris females was reduced by dual exposure to novaluron treated potato plants and larvae. Some control females were lost during the experiment, which reduced the sample size and variance of the control, producing a statistically significant result. Nonetheless, at the end of the experiment most remaining adults were alive in the controls (6 of 8), while few remained in the novaluron treatments (2 of 19). Although we ended the experiment at 21 days due to reduced quality of experimental plants, it is likely that adults in the controls could have survived well beyond this point since those used in our rearing procedures routinely survive over 2 months. The observations that $P$. maculiventris adults in the novaluron treatments were often ataxic or immobilized on their backs for prolonged periods provide further evidence of sublethal intoxication. Similar effects were observed in $L$. decemlineata adults after prolonged exposure to novaluron treated potato foliage (Cutler et al., 2005a).

Reduced fecundity and egg viability in adult $L$. decemlineata exposed to novaluron treated potato foliage was previously reported (Cutler et al., 2005a; Malinowski and Pawinska, 1992). These effects also occurred in P. maculiventris adults placed on novaluron treated potato foliage with $L$. decemlineata larvae. Adults in treatments laid only $35-60 \%$ of the eggs laid by those on untreated foliage. These reduced reproductive outputs may have been due to effects on reproductive systems, suboptimal nutrition due to reduced feeding, altered mating behavior as a result of sublethal intoxication, or a combination of factors. More importantly, however, egg hatch and molt of emerged nymphs in the novaluron treatments was almost completely arrested. The experimental design employed is probably a worst case scenario as $P$. maculiventris populations in the field would likely have access to novaluron-free refugia. Additionally, rainfall and UV radiation would undoubtedly reduce duration of the biological activity of novaluron in the field compared to our laboratory set-up. Nonetheless, foliar applied novaluron has very persistent biological activity under field conditions (Cutler et al., 2005b; Ishaaya et al., 1998, 2002, 2001), suggesting longterm adverse effects on $P$. maculiventris adults could occur under field conditions. In contrast to these results, diflubenzuron and pyriproxyfen (De Clercq et al., 1995), diafenthiuron and imidacloprid (De Cock et al., 1996), and deltamethrin (Mohaghegh et al., 2000) had no effect on P. maculiventris oviposition. However, whereas the present study exposed adults for 21 days to plants treated with field rates of insecticide and prey that fed upon the treated foliage, in two of these studies $P$. maculiventris was exposed to sublethal doses of insecticide (De Clercq et al., 1995;
De Cock et al., 1996), and in all three studies exposure time was shorter.

Use of selective insecticides is an effective strategy for conservation biological control, as well as natural enemy augmentations. Novaluron has demonstrated good selectivity against several beneficial insects making it a valuable tool in several IPM programs. However, our results indicate that all $P$. maculiventris life stages are susceptible to novaluron through various routes of exposure. Although there are numerous factors to consider when extrapolating laboratory data to the field, results of the present laboratory experiments suggest that applications of novaluron against pests like $L$. decemlineata would probably have little selectivity in favor of $P$. maculiventris populations.

\section{Acknowledgments}

This work was funded by an Ontario Graduate Scholarship and J.H. Stewart Reid Memorial Fellowship (Canadian Association of University Teachers) to G.C.C. Additional support was provided by the Ontario Ministry of Agriculture and Food-University of Guelph Plants Program, and Agriculture and Agri-Food Canada (Southern Crop Protection and Food Research Centre, London, ON). The technical assistance of Brian Beattie, Claudia Lafreniere, Jason Sproule, and Jay Whistlecraft is gratefully acknowledged.

\section{References}

Biever, K.D., Chauvin, R.L., 1992. Suppression of the Colorado potato beetle (Coleoptera: Chrysomelidae) with augmentative releases of predaceous stinkbugs (Hemiptera: Pentatomidae). J. Econ. Entomol. $85,720-726$.

Bishop, B.A., Grafius, E.J., 1996. Insecticide resistance in the Colorado potato beetle. In: Jolivet, P.H.A., Cox, M.L. (Eds.), Chrysomelidae Biology: The Classification, Phylogeny and Genetics. SPB Academic publishing, Amsterdam, pp. 355-377.

Cabrera, A.R., Cloyd, R.A., Zaborski, E.R., 2005. Lethal and sub-lethal effects of novaluron (Pedestal) on the soil-dwelling predatory mite, Stratiolaelaps scimitus (Womersley) (Acari: Mesostigmata: Laelapidae), under laboratory conditions. J. Entomol. Sci. 40, 47-53.

Casagrande, R.A., 1987. The Colorado potato beetle: 125 years of mismanagement. Bull. Entomol. Soc. Amer. 33, 142-150.

Cloutier, C., Bauduin, F., 1995. Biological control of the Colorado potato beetle Leptinotarsa decemlineata (Coleoptera: Chrysomelidae) in Quebec by augmentative releases of the two-spotted stinkbug Perillus bioculatus (Hemiptera: Pentatomidae). Can. Entomol. 127, 195-212.

Cloutier, C., Boiteau, G., Geottel, M.S., 2002. Leptinotarsa Decemlineata (Say), Colorado potato beetle (Coleoptera: Chrysomelidae). In: Mason, P.G., Huber, J.T. (Eds.), Biological Control Programmes in Canada, 1981-2002. CABI Publishing, New York, pp. 145-152.

Cloutier, C., Jean, C., 1998. Synergism between natural enemies and biopesticides: a case using the stinkbug Perillus bioculatus (Hemiptera: Pentatomidae) and Bacillus thuringiensis tenebrionis against Colorado potato beetle (Coleoptera: Chrysomelidae). J. Econ. Entomol. 91, 1096-1108

Coll, M., Ruberson, J.R.E., 1998. Predatory Heteroptera: Their Ecology and Use in Biological Control. Entomological Society of America, Lanham.

Cutler, G.C., Scott-Dupree, C.D., Tolman, J.H., Harris, C.R., 2005a. Acute and sublethal toxicity of novaluron, a novel chitin synthesis 
inhibitor, to Leptinotarsa decemlineata (Coleoptera: Chrysomelidae). Pest Manag. Sci. 61, 1060-1068.

Cutler, G.C., Tolman, J.H., Scott-Dupree, C.D., Harris, C.R., 2005 b. Resistance potential of Colorado potato beetle (Coleoptera: Chrysomelidae) to novaluron. J. Econ. Entomol. 98, 1685-1693.

De Clercq, P., De Cock, A., Tirry, L., Vinuela, E., Degheele, D., 1995. Toxicity of diflubenzuron to the predatory bug Podisus maculiventris. Entomol. Exp. Appl. 74, 17-22.

De Cock, A., De Clercq, P., Tirry, L., Degheele, D., 1996. Toxicity of diafenthiuron and imidacloprid to the predatory bug Podisus maculiventris (Heteroptera: Pentatomidae). Environ. Entomol. 25, 476-480.

Ferro, D.N., 1994. Biological control of the Colorado potato beetle. In: Zehnder, G.W., Powelson, M.L., Jansson, R.K., Raman, K.V. (Eds.), Advances in Potato Pest Biology and Management. APS Press, St. Paul, pp. 357-375.

Hare, J.D., 1990. Ecology and management of the Colorado potato beetle. Annu. Rev. Entomol. 35, 81-100.

Harris, C.R., Manson, G.F., Mazurek, J.H., 1962. Development of insecticidal resistance by soil insects in Canada. J. Econ. Entomol. 55, 777-780.

Hilbeck, A., Eckel, C., Kennedy, G., 1998. Impacts of Bacillus thuringiensis insecticides on population dynamics and egg predation of the Colorado potato beetle in North Carolina potato plantings. Biol. Control 43, 65-75.

Hough-Goldstein, J., Keil, C.B., 1991. Prospects for integrated control of the Colorado potato beetle (Coleoptera: Chrysomelidae) using Perillus bioculatus (Hemiptera: Pentatomidae) and various pesticides. J. Econ. Entomol. 84, 1645-1651.

Hough-Goldstein, J.A., 1996. Use of predaceous pentatomids in integrated management of Colorado potato beetle (Coleoptera: Chrysomelidae). In: Coll, M., Ruberson, J. (Eds.), Predatory Heteroptera in Agroecosystems: Their Ecology and Biological Control. Thomas Say Publications, Lanham, pp. 209-223.

Hough-Goldstein, J.A., McPherson, D., 1996. Comparison of Perillus bioculatus and Podisus maculiventris (Hemiptera: Pentatomidae) as potential control agents of the Colorado potato beetle (Coleoptera: Chrysomelidae). J. Econ. Entomol. 89, 1116-1123.

Ishaaya, I., Damme, N., Tirry, L., 1998. Novaluron, optimization and use for the control of the beet armyworm and greenhouse whitefly. In: Proc. Brighton Crop Prot. Conf.-Pests Dis., Vol. 1, BCPC, Farnham, Surrey, pp. 49-56.

Ishaaya, I., Horowitz, A.R., Tirry, L., Barazani, A., 2002. Novaluron (Rimon) a novel IGR: mechanism, selectivity and importance in IPM programs. Med. Fac. Landbouww. Univ. Gent. 67, 617-626.

Ishaaya, I., Kontsedalov, S., Mazirov, D., Horowitz, A.R., 2001. Biorational agents: mechanisms and importance in IPM and IRM programs for controlling agricultural pests. Med. Fac. Landbouww. Univ. Gent. 66, 363-374.

Ishaaya, I., Yablonski, S., Mendelson, Z., Mansour, Y., Horowitz, A.R., 1996. Novaluron (MCW-275), a novel benzoylphenyl urea, suppressing developing stages of lepidopteran, whitefly and leafminer pests. In: Proc. Brighton Crop Prot Conf.-Pest Dis, Vol. 3, BCPC, Farnham, Surrey, pp. 1013-1020.
Koss, A.M., Jensen, A.S., Schreiber, A., Pike, K.S., Snyder, W.E., 2005. Comparison of predator communities in Washington potato fields treated with broad-spectrum, selective, or organic insecticides. Environ. Entomol. 34, 87-95.

Malinowski, H., Pawinska, M., 1992. Comparative evaluation of some chitin synthesis inhibitors as insecticides against Colorado potato beetle Leptinotarsa decemlineata (Say). Pestic. Sci. 35, 349-353.

McPherson, J.E., 1982. The Pentatomoidea (Hemiptera) of Northeastern North America with Emphasis on the Fauna of Illinois. Southern Illinois University Press, Carbondale.

Mohaghegh, J., De Clercq, P., Tirry, L., 2000. Toxicity of selected insecticides to the spined soldier bug Podisus maculiventris (Heteroptera: Pentatomidae). Biocontrol Sci. Technol. 10, 33-44.

Mota-Sanchez, D., Hollingworth, R.M., Grafius, E.J., Moyer, D.D., 2005. Resistance and cross-resistance to neonicotinoid insecticides and spinosad in the Colorado potato beetle, Leptinotarsa decemlineata (Say) (Coleoptera: Chrysomelidae). Pest Manag. Sci. 62, 30-37.

OMAF, 2004. Publication 363: Vegetable Production Recommendations, 2004-2005. Queen's Printer for Ontario, Toronto.

Reed, G.L., Jensen, A.S., Riebe, J., Head, G., Duan, J.J., 2001. Transgenic Bt potato and conventional insecticides for Colorado potato beetle management: comparative efficacy and non-target impacts. Entomol. Exp. Appl. 100, 89-100.

Retnakaran, A., Wright, J.E., 1987. Control of insect pest with benzoylphenyl ureas. In: Wright, J.E., Retnakaran, A. (Eds.), Chitin and Benzoylphenyl Ureas. Dr. W. Junk Publ, Dordrecht, pp. 205-282.

Ruberson, J.R., Tauber, M.J., Tauber, C.A., 1986. Plant feeding by Podisus maculiventris (Heteroptera: Pentatomidae): effect on survival, development, and preoviposition period. Environ. Entomol. 15, 894 897.

SAS Institute. 1997. JMP IN version 3.2. SAS Institute, Cary, NC.

SAS Institute, 2001. SAS System for Windows, Release 8.2. SAS Institute, Cary, NC.

Schaefer, C.W., Panizzi, A.R.E., 2000. Heteroptera of Economic Importance. CRC Press, LLC, Boca Raton.

Starks, J.D., Banks, J.E., 2003. Population-level effects of pesticides and other toxicants on arthropods. Annu. Rev. Entomol. 48, 505-519.

Tillman, P.G., Mullinix, B.G., 2004. Comparison of susceptibility of pest Euschistus servus and predator Podisus maculiventris (Heteroptera : Pentatomidae) to selected insecticides. J. Econ. Entomol. 97, 800-806.

Vandekerkhove, B., De Clercq, P., 2004. Effects of an encapsulated formulation of lambda-cyhalothrin on Nezara viridula and its predator Podisus maculiventris (Heteroptera: Pentatomidae). Fla. Entomol. 87, 112-118.

Wilkinson, J.D., Biever, K.D., Ignoffo, C.M., 1979. Synthetic pyrethroid and organophosphorous insecticides against the parasitoid Apanteles marginiventris and the predators Geocoris punctipes, Hippodamia convergens, and Podisus maculiventris. J. Econ. Entomol. 72, 473-475.

Yu, S.J., 1988. Selectivity of insecticides to the spined soldier bug (Heteroptera: Penatomidae) and its lepidopterous prey. J. Econ. Entomol. 81, 119-122.

Zar, J.H., 1996. Biostatistical Analysis. Prentice-Hall, Upper Saddle River. 